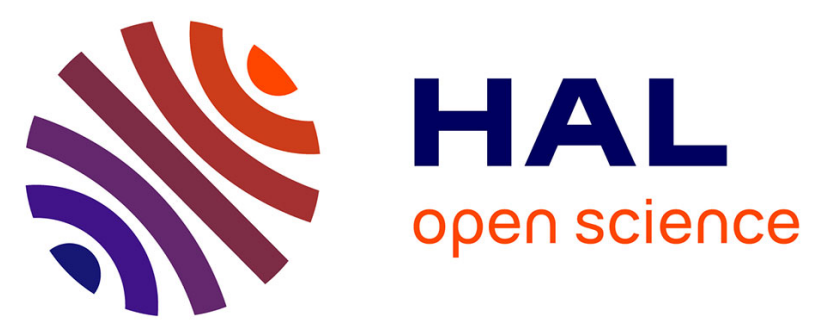

\title{
The alkyl polyglucoside/fatty alcohol ratio effect on the formation of liquid crystal phases in binary systems
}

Daria Terescenco, Géraldine Savary, Florence Clemenceau, Emmanuelle Merat, Benoit Duchemin, Michel Grisel, Celine Picard

\section{- To cite this version:}

Daria Terescenco, Géraldine Savary, Florence Clemenceau, Emmanuelle Merat, Benoit Duchemin, et al.. The alkyl polyglucoside/fatty alcohol ratio effect on the formation of liquid crystal phases in binary systems. Journal of Molecular Liquids, 2018, 253, pp.45-52. 10.1016/j.molliq.2017.12.149 . hal-02507804

\section{HAL Id: hal-02507804}

\section{https://hal-normandie-univ.archives-ouvertes.fr/hal-02507804}

Submitted on 8 May 2020

HAL is a multi-disciplinary open access archive for the deposit and dissemination of scientific research documents, whether they are published or not. The documents may come from teaching and research institutions in France or abroad, or from public or private research centers.
L'archive ouverte pluridisciplinaire HAL, est destinée au dépôt et à la diffusion de documents scientifiques de niveau recherche, publiés ou non, émanant des établissements d'enseignement et de recherche français ou étrangers, des laboratoires publics ou privés. 


\title{
The alkyl polyglucoside/fatty alcohol ratio effect on the formation of liquid crystal phases in binary systems
}

\author{
Daria Terescenco ${ }^{1}$, Geraldine Savary ${ }^{1}$, Florence Clemenceau ${ }^{2}$, Emmanuelle Merat $^{2}$, Benoit Duchemin ${ }^{3}$, Michel Grisel $^{1}$, Celine \\ Picard $^{1} *$ \\ ${ }^{1}$ Normandie Univ, UNILEHAVRE, FR 3038 CNRS, URCOM, 76600 Le Havre, France \\ ${ }^{2}$ Direction Innovation - UID Excipients SEPPIC, 127 Chemin de la Poudrerie, 81105 Castres Cedex, France \\ ${ }^{3}$ Normandie Univ, UNIHAVRE, CNRS, LOMC, 76600 Le Havre, France \\ daria.terescenco@univ-lehavre.fr \\ geraldine.savary@univ-lehavre.fr \\ florence.clemenceau@airliquide.com \\ emmanuelle.merat@airliquide.com \\ benoit.duchemin@univ-lehavre.fr \\ michel.grisel@univ-lehavre.fr \\ celine.picard@univ-lehavre.fr \\ * Corresponding author.
}

TEL: +33232744394 


\section{Keywords}

Surfactant; Alkyl polyglucoside; Lyotropic Liquid crystals; $\alpha$-gel; WAXD; auto-emulsion; molecular organization

\section{Abbreviations}

APG: alkyl polyglucoside

APG/FA: alkyl polyglucoside/ fatty alcohol

CMC: critical micelle concentration

SLS: static light scattering

WAXD: wide-angle X-ray diffraction

\section{Highlights}

- Alkylpolyglucoside/fatty alcohol emulsifier a precursor of liquid crystals formation

- Type of liquid crystals linked to the alkylpolyglucoside/fatty alcohol ratio

- Presence of fatty alcohol - an indispensable condition for lamellar phase formation

- Impact of surfactants molecular organization on systems final properties

- WAXD - adapted technique to distinguish different types of the lamellar phase 


\section{Abstract}

The present research focuses on the alkyl polyglucoside, a non-ionic surfactant, in combination with a fatty alcohol of the same chain length used as a co-surfactant. A series of solutions were prepared, with varying both APG/FA ratio and its concentration in water. Different structures were then obtained, depending on these two parameters: aqueous micellar solutions, normal hexagonal liquid crystalline phase, $\alpha$-gel phase, as well as the mixture of normal hexagonal / $\alpha$-gel phases. A specific term "autoemulsion" was introduced to describe the pseudo emulsions formed by the APG $\angle F A$ containing solutions because of the fatty alcohol, which dispersion in water was similar to an emulsion representation. The presence of the liquid crystals was revealed by optical microscopy under the polarized light, as different anisotropic conformations corresponding to the lamellar phase, the hexagonal phase and the coexistence of the lamellar and hexagonal phases, mainly for the most concentrated samples, were observed. These structures were characterized at the molecular level through the wide-angle X-ray diffraction technique and their macroscopic behaviour was investigated by rheology tests. Two main observations were then made: the variation of the surfactant concentration in solution promotes the transition between micellar region towards the liquid crystalline formation zone, while the APG/FA ratio impacts the formation of hexagonal phases (APG $>$ FA) or of lamellar ones (APG<FA).

\section{Introduction}

Surfactants are among the most important raw materials of the chemical industry. They are known for an important number of applications in petroleum industries, pharmaceutical domain, food industry, high-technology areas, biotechnology, cosmetics, paints, from primary production processes to improve the quality of finished products [1]. The properties and the applications of the surfactants are determined by the balance between the lipophilic and hydrophilic portions of the molecules, which means that such properties as solubility, surface tension reducing capability, critical micelle concentration, detergency power, wetting control make a given surfactant more useful in some domains and less in others [2].

Due to its amphiphilic structure, surfactant molecules spontaneously aggregate in solution to form a variety of thermodynamically stable structures, thus these association colloids have the capacity to solubilize nonpolar materials in polar medium and the ability to cause depletion flocculation of dispersions or emulsions [3]. Depending on the surfactant concentration in aqueous solution, and after attending the CMC, it can form structures such as micelles [4], isotropic solutions with low viscosity [5] or cylindrical structures, and then, once the necessary concentration is reached, the surfactant can form liquid crystals. A large variety of liquid crystals formations exist, but the widest are of three types: hexagonal, lamellar or cubic phases [6]. Liquid crystals possess liquid and solid properties at the same time as they are more organized than liquids, but less than solids [7].

In the industry, the lamellar phase is the starting system for some detergents products and processes, as spray-drying, chilling and milling, while lyotropic mixtures with hexagonal and isotropic phases are used in the automobile industry and in the manufacture of textile soaps. In food domain, the lyotropic mixtures are investigated in the case of lipids and mostly for emulsions formulation [8].

Choosing the appropriate emulsifier is of primary importance as it helps to improve both the stability and the quality of dispersions/emulsions. Consequently, understanding the physicochemical properties of the emulsifier, its capacity to interact with other molecules and to form specific microstructures such as lyotropic liquid crystals, is essential for controlling the properties of the final products [9].

In the context of growing concern for the environment, natural-based surfactants became popular as an alternative to the synthetic ones. Alkyl polyglucoside (APG) is one of the well-known families of natural surfactants, derived from natural glucose and a fatty alcohol; it is therefore considered as non-toxic, mild and environmentally friendly emulsifier [10]. The APG, paired with a fatty alcohol (FA) with the same chain length is known for its ability to form lamellar liquid crystal [11], which can be involved in the emulsion stabilization process [12]. In those studies, only one specific APG/FA ratio based on commercial availability was investigated, used mostly in cosmetic and pharmaceutical fields[11,13-15], thus making interesting the revealing of other possible structures which can be formed by varying the APG/FA ratio. In their work, Platz et al. [16] described the lamellar phases created by the dodecyl and tetradecyl D-glucopyranoside coupled with different fatty alcohols of smaller or similar chain length, but no other types of liquid crystals were evidenced. Consequently, there is a gap in understanding of the 
liquid crystal formation mechanism when considering the combination of alkyl polyglucoside and a fatty alcohol of the same chain length.

The purpose of this research is to describe the phase behaviour of the $C_{16} C_{18}$ polyglucoside emulsifier coupled to $C_{16} C_{18}$ fatty alcohol. Thirty-six solutions were prepared by varying the ratios of the surfactant/co-surfactant and its concentration in solution. Then, different techniques, namely microscopy, rheology, droplet size distribution and X-rays diffraction analysis were used to describe their properties.

\section{$2 \quad$ Materials and methods}

\subsection{Materials and sample preparation}

The fatty alcohol (provided by SEPPIC, France), produced from a vegetable oil source, is composed of "cetostearyl alcohol" that is a mixture of $\mathrm{C}_{16} / \mathrm{C}_{18}$ alkyl chains. The proportion of each fatty alcohol is constant in the rest of the study, fixed by the vegetable oil source. It served as a raw material for the alkyl polyglucoside synthesis. After the glycosidation of the fatty alcohol, a mixture of $\mathrm{C}_{16} \mathrm{C}_{18} \mathrm{APG}_{1.3}$ and $\mathrm{C}_{16} \mathrm{C}_{18} \mathrm{OH}$ is obtained. The most concentrated in APG sample, 84.5 APG/15.5 FA, was completed with the same fatty alcohol to obtain different ratios: 70 APG/30 FA, 60 APG/ 40 FA, 50 APG/ 50 FA, 30 APG/70 FA and 20 APG/ 80 FA. Consequently, for different ratios, the alkyl chain length (of the APG and the FA) is always the same.

These ratios were used in order to prepare a series of solutions with concentrations ranging from $0.5 \%$ to $30 \%$ (w\%/w\%) in water, as presented in Table 1 . Thus, the corresponding system only consisted of the emulsifier mixture and water, with Phenoxyethanol and Methylparaben and Ethylparaben and Propylparaben and Butylparaben at 1\% (Sepicide HB, SEPPIC, France) used as preservative.

Table 1. 36 solutions with the percentage of APG and FA (w\%/w\%) in the total composition of the formulation, function of the ratio and its concentration in each solution.

\begin{tabular}{ccccccc}
\hline $\begin{array}{c}\text { Ratio } \\
\text { APG/FA }\end{array}$ & $\mathbf{0 . 5 \%}$ & $\mathbf{1} \%$ & $\mathbf{2 . 5 \%}$ & $\mathbf{5} \%$ & $\mathbf{1 0 \%}$ & $\mathbf{3 0 \%}$ \\
\hline \multirow{2}{*}{$\mathbf{8 4 . 5 / 1 5 . 5}$} & $0.42 \%$ APG / & $0.85 \%$ APG / & $2.11 \%$ APG / & $4.23 \%$ APG / & $8.45 \%$ APG / & $25.35 \%$ APG / \\
& $0.08 \%$ FA & $0.15 \%$ FA & $0.39 \%$ FA & $0.78 \%$ FA & $1.55 \%$ FA & $4.65 \%$ FA \\
\hline \multirow{2}{*}{$\mathbf{7 0 / 3 0}$} & $0.35 \%$ APG / & $0.7 \%$ APG / & $1.75 \%$ APG / & $3.5 \%$ APG / & 7\% APG / & $21 \%$ APG / \\
& $0.15 \%$ FA & $0.3 \%$ FA & $0.75 \%$ FA & $1.5 \%$ FA & $3 \%$ FA & $9 \%$ FA \\
\hline \multirow{2}{*}{$\mathbf{6 0 / 4 0}$} & $0.3 \%$ APG / & $0.6 \%$ APG / & $1.5 \%$ APG / & $3 \%$ APG / & $6 \%$ APG / & $18 \%$ APG / \\
& $0.2 \%$ FA & $0.4 \%$ FA & $1 \%$ FA & $2 \%$ FA & $4 \%$ FA & $12 \%$ FA \\
\hline \multirow{2}{*}{$\mathbf{5 0 / 5 0}$} & $0.25 \%$ APG / & $0.5 \%$ APG / & $1.25 \%$ APG / & $2.5 \%$ APG / & $5 \%$ APG / & $15 \%$ APG / \\
& $0.25 \%$ FA & $0.5 \%$ FA & $1.25 \%$ FA & $2.5 \%$ FA & $5 \%$ FA & $15 \%$ FA \\
\hline \multirow{2}{*}{$\mathbf{3 0 / 7 0}$} & $0.15 \%$ APG / & $0.3 \%$ APG / & $0.75 \%$ APG / & $1.5 \%$ APG / & $3 \%$ APG / & $9 \%$ APG / \\
& $0.35 \%$ FA & $0.7 \%$ FA & $1.75 \%$ FA & $3.5 \%$ FA & $7 \%$ FA & $21 \%$ FA \\
\hline \multirow{2}{*}{$\mathbf{2 0 / 8 0}$} & $0.1 \%$ APG / & $0.2 \%$ APG / & $0.5 \%$ APG / & $1 \%$ APG / & $2 \%$ APG / & $6 \%$ APG / \\
& $0.4 \%$ FA & $0.8 \%$ FA & $2 \%$ FA & $4 \%$ FA & $8 \%$ FA & $24 \%$ \\
\hline
\end{tabular}

Systems were prepared by heating the deionized water and emulsifier up to $80^{\circ} \mathrm{C}$ under mechanical stirring (400rpm-600rpm). It was then homogenized at 10,000 rpm during one minute using a T25 digital ultra-turrax (IKA, Freiburg, Germany) equipped with the dispersing head S25N-25F. Mixtures were then cooled down to $30^{\circ} \mathrm{C}$ under stirring (between $200 \mathrm{rpm}$ and $400 \mathrm{rpm}$, depending on the product's consistency) and then the preservative was added. Once prepared, the products were divided into three samples, stocked at $4^{\circ} \mathrm{C}, 40^{\circ} \mathrm{C}$ and ambient temperature, respectively, for stability monitoring.

\section{$2.2 \quad$ Methods}

\subsubsection{Microscopy}

The microstructure was analysed by means of a light photomicroscope (Leica DMLP microscope) equipped with a video camera: firstly, under the bright field and secondly, under the polarized light (using cross-polarizers) in order to investigate the presence of liquid crystalline phases in each sample. Leica IM 1000 software was used to analyse the obtained micrographs. 


\subsubsection{Droplet size distribution}

The auto-emulsion droplet size, as well as the droplet size distribution, was measured by static light scattering (SLS) using a laser diffraction particle size analyser SALD-7500 nano (Shimadzu Co., Ltd, Japan) equipped with a violet semiconductor laser (405 NM) and a reverse Fourier optical system (the beam converge before encountering the sample). The auto-emulsions were diluted in deionized water in order to achieve the absorption parameter equal to 0.2 . Once introduced into the batch cell ( 7 $\mathrm{cm}^{3}$ ), the auto-emulsions were stirred during the measurement to ensure sample homogeneity. Data were analysed using Wing SALD II software.

\subsubsection{Rheological measurements}

Continuous and oscillatory measurements were performed using a controlled stress rheometer (HR1, TA instruments). A coneplate aluminium device was used, with a diameter of $40 \mathrm{~mm}$, a cone angle of $1^{\circ} 59^{\prime} 38^{\prime \prime}$ and a gap of $47 \mu \mathrm{m}$. All the measurements were carried out in duplicate at $25^{\circ} \mathrm{C}$. Samples were loaded with a spatula, and a solvent trap was used to prevent sample drying. Once loaded, all samples were left at rest for two minutes prior to any measurement.

During continuous ramp testing, the flow properties were obtained by recording shear stress and viscosity values at shear rates increasing from 0.001 to $8000 \mathrm{~s}^{-1}$ (logarithmic mode) for $300 \mathrm{~s}$.

The linear viscoelastic region was obtained through oscillatory measurements conducted at $1 \mathrm{~Hz}$ with an increasing strain from $0.1 \%$ to $100 \%$ (logarithmic mode). The frequency sweep ramp was performed from 0.01 to $10 \mathrm{~Hz}$ at a constant strain remaining within the previously marked linear viscoelastic region of each sample. Then, storage ( $\left.G^{\prime}\right)$ and loss moduli (G") were reported for the rheological characterization of investigated samples.

\subsubsection{Wide-angle X-ray diffraction (WAXD)}

Samples were analysed in reflection mode by X-ray diffraction (XRD) using a PANalytical Xpert Powder diffractometer (PANalytical B.V., Almelo, The Netherlands) with a CoKa ( $\lambda=1.7902 \AA)$ monochromatic radiation source; operating voltage and current were maintained at $40 \mathrm{KV}$ and $40 \mathrm{MA}$, respectively. A $15 \mathrm{~mm}$ mask was used. The detector was a linear PIXcel1D detector. Data were acquired by $0.02^{\circ}$ steps for $2 \theta$ values ranging from 2 to $50^{\circ}$. Specific sample holders were filled with the formulation and carefully sealed with kapton foils in order to avoid evaporation during measurements. The interlayer spacings were calculated from diffraction angle theta $(\theta)$ according to Bragg's law. 


\subsection{Phase diagram}

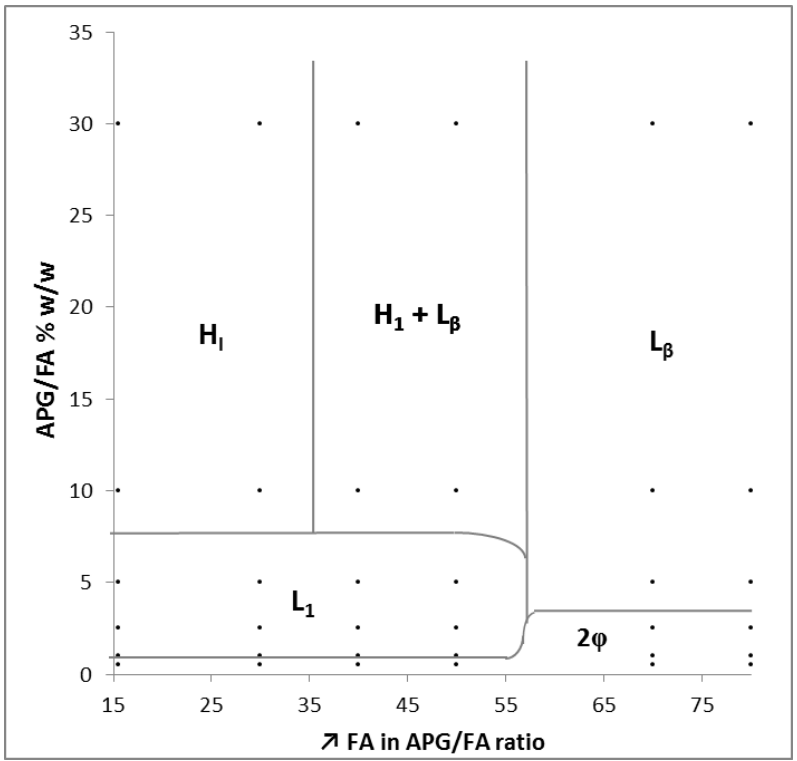

Figure 1. 2-D phase diagram of $C_{16} C_{18} A P G / C_{16} C_{18} O H$ mixed emulsifier. X-axis represents $A P G / F A$ ratio variation, by increasing the fatty alcohol proportion (84.5APG/15.5FA, 70APG/30FA, 60APG/40FA, 50APG/50FA, 30APG/70FA, 20APG/80FA) plotted against the concentrations values in water $(0.5 \%, 1 \%, 2.5 \%, 5 \%, 10 \%, 30 \%)$, represented by $y$-axis. $2 \varphi$ is an instability zone, $L_{1}$ micellar region, $H_{1}$ hexagonal phase, $L_{\beta}-$ lamellar alpha gel phase, and $\mathrm{H}_{1}+\mathrm{L}_{\beta}$ the mixture of hexagonal and lamellar phases.

The phase behaviour of the studied mixed emulsifier is plotted in Figure 1. Five distinct regions were obtained depending on the emulsifiers' concentration and the ratio of the APG and FA: two-phase region for the small quantities of the surfactant progresses towards the micellar solution zone and next, to liquid crystal zone of hexagonal type (when APG>FA) or a mixture of hexagonal and lamellar type (when APG=FA). For the APG<FA systems, the $\alpha$-gel organization was confirmed. Moreover, it this zone, the formation of so-called auto-emulsions was observed. In these particular systems, the excess of the fatty alcohol plays the complementary role of the oil phase in the system, favouring the formation of a pseudo emulsion. This system will be further discussed.

The first information about the phase diagram was revealed by microscopy under the bright and polarized light (Figure 2). 

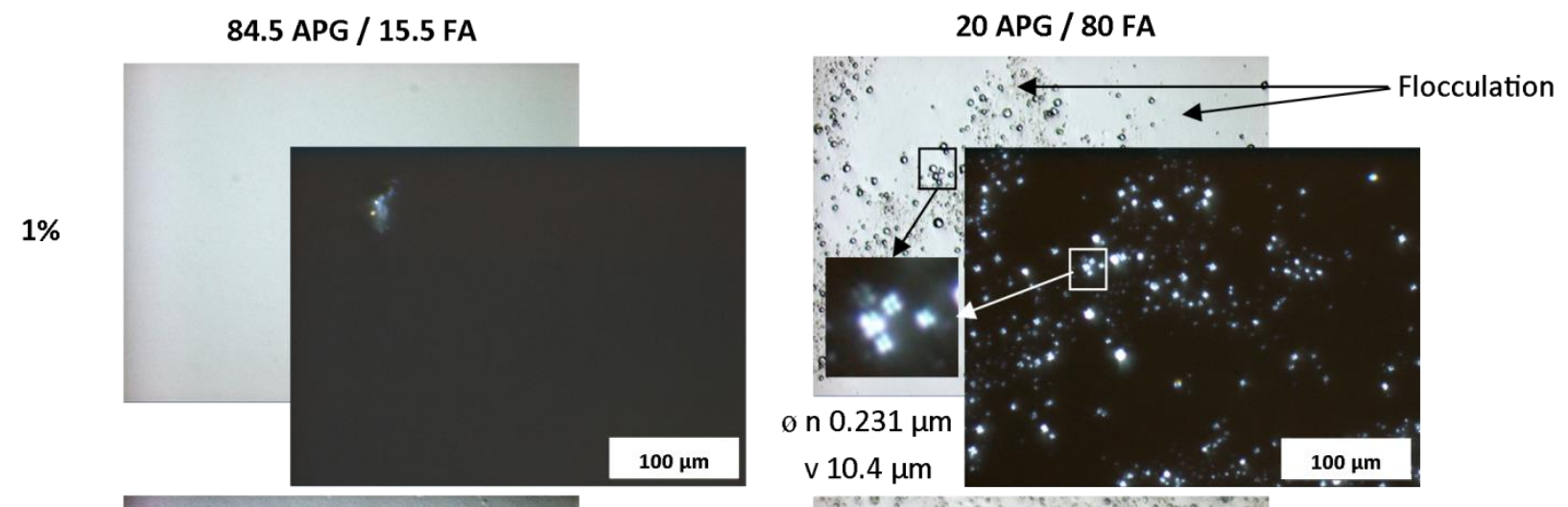

$5 \%$
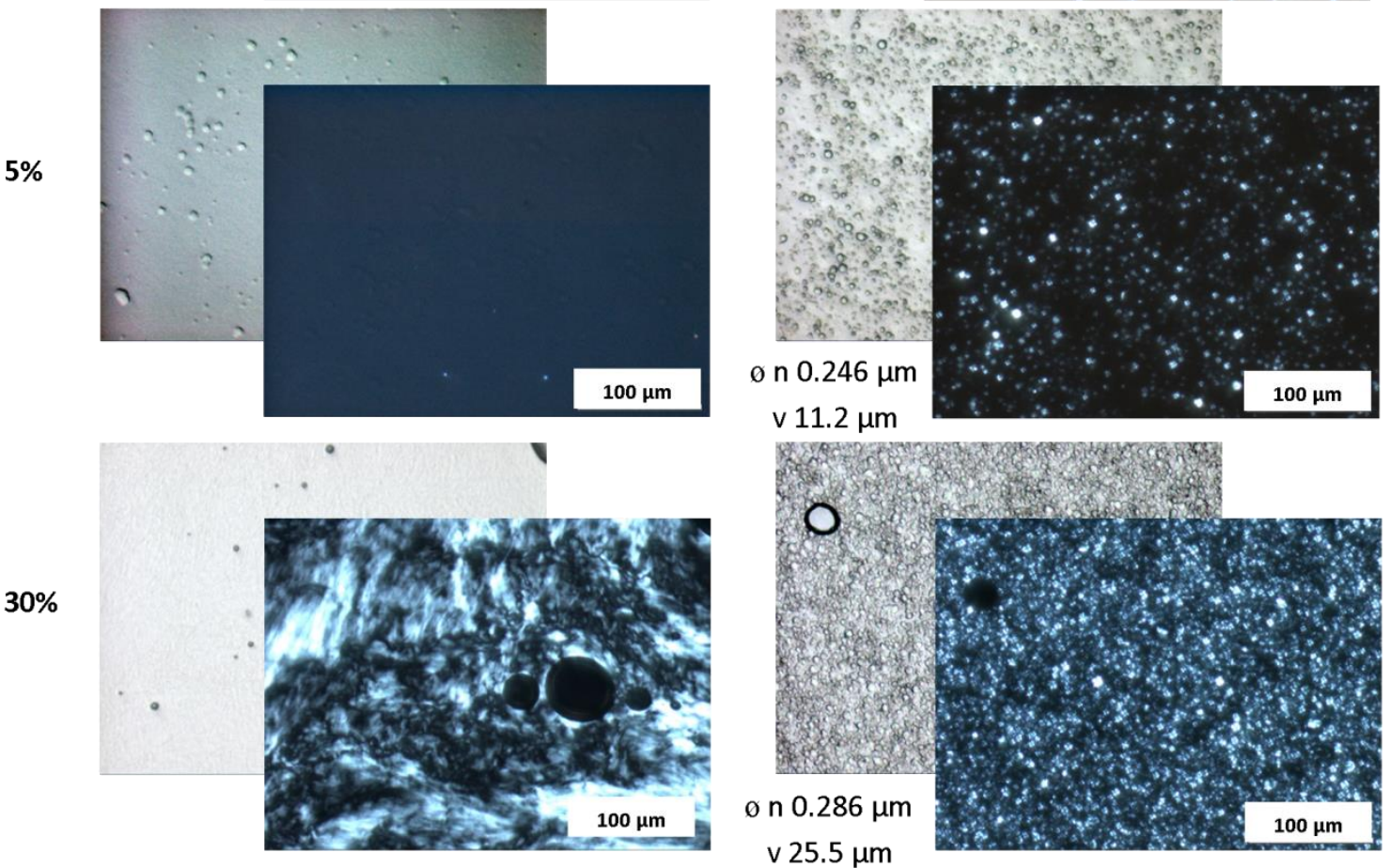

Figure 2. Micrographs under the bright and polarized light of two ratios at $1 \%, 5 \%$ and $30 \%$ in solution. For 84.5 APG/ 15.5 FA (left part), two micellar solutions are followed by the hexagonal specific texture under the polarized light. For and 20 APG/80 FA (right part), pseudo droplets of fatty alcohol are formed ( $\varnothing$ - median diameter in number and volume), seen as Maltese Crosses under the polarized light.

It will be further discussed during step by step analysis of each region.

\subsection{Two-phase and micellar solution regions}

Liquid solutions were first analysed by light microscopy, one day after preparation $\left(T_{0}+24 h\right)$. Mixtures properties were different depending on the APG/FA ratio. Systems with APG>FA did not show any particular objects under the bright light, suggesting the occurrence of micellar solutions [16]; this was confirmed by the absence of birefringence under the polarized light.

On the other hand, for liquid formulations with APG<FA, real droplets under the bright light were observed (Fig.2), which could be seen under the polarized light as Maltese crosses, therefore attesting the presence of lamellar phases[17,18] in the system.

These results suggest that even at low surfactant concentrations, increasing the fatty alcohol ratio promotes the occurrence of lamellar phases.

There exist different types of lamellar phases, $L_{\alpha}, L_{\beta}, L_{\psi}, L_{\beta^{\prime}}, L_{\delta}, L_{s}$, and $P_{\beta^{\prime}}$, each being observed in lyotropic phase diagrams [19], but two main lamellar organizations are more common, namely lamellar liquid crystals $\left(L_{\alpha}\right)$ and $\alpha$-gel $\left(L_{\beta}\right)$. In the $L_{\alpha}$ phase, the 
hydrocarbon chains are in a liquid-like state, while in the $L_{\beta}$ phase, the hydrocarbon chains remain stiff, perpendicular to the plane of the lamellae with the axes organized as a two-dimensional hexagonal lattice[8]. The type of the formed lamellar phase cannot be distinguished through microscopic analysis, so other complementary techniques were necessary to confirm the different hypotheses, such as rheological tests and wide-angle X-rays diffraction.

The interest of this observation lays in physical differences between the formulated products. For the same surfactant concentration, the APG/FA ratio guides the formulation properties. The importance of the fatty alcohol in the lamellar phase formation, as a co-surfactant, was already evoked in the literature [20-22]. For the pure APG emulsifier, the lamellar phase occurs at high surfactant concentrations [23], while adding the fatty alcohol as co-surfactant at more than 50\% provokes lamellar phase formation even at very low mixed emulsifier concentration.

Meanwhile, the stability of these liquid formulations was questioned. Despite the formation of liquid crystals, which are involved in the auto-emulsions stabilization process, the samples containing from $0.5 \%$ to $2.5 \%$ of emulsifier with $20 / 80$ and $30 / 70$ APG/FA ratio, destabilized by creaming. It was spontaneous for the samples containing less APG, lasted one day for $0.5 \%$, or took nearly one week for $2.5 \%$ considering the samples kept at $40^{\circ} \mathrm{C}$ (accelerated ageing). The samples stored at the ambient temperature needed few days longer to accomplish the destabilization process. At the same time, the systems corresponding to $A P G \geq F A$ ratios at a minimal concentration of $1 \%$ remained stable over the timescale of the study.

The first signs of instability were already seen under the bright light (Fig.2 - Flocculation). In order to understand the mechanism of creaming, the microstructure of the two separated phases was checked. All the Maltese Crosses, corresponding to the lamellar phase, were compiled together in the upper phase, over the rejected water. With increasing the concentration of the emulsifier in the formulation between $0.5 \%$ and $2.5 \%$ the thickness of the upper phase increased, thus evidencing the expansion of the lamellar liquid crystals in the matrix. Finally, once the sufficient concentration of surfactant mixture was reached (over $2.5 \%)$, the amount of formed liquid crystals is sufficient to ensure the whole mixture's physical stability.

\subsection{Micellar solution - liquid crystal transition}

To complete microscopic observations, systems were characterized by flow and viscoelastic tests. In particular, it was decided to focus on series at $5 \%$ of emulsifier as, at this concentration, the transition between the micellar phase and liquid crystals is observed (Fig. 1).

In order to confirm visual observations, the oscillatory test was first considered. For the formulations containing $5 \%$ of emulsifier with 70/30 APG/FA, the loss modulus G" is superior to the storage modulus $\mathrm{G}^{\prime}$, revealing the predominant viscous behaviour of the product (Fig.3a). On the contrary, for 20/80 APG/FA, the elastic ( $G^{\prime}$ ) response is higher than the viscous one ( $G^{\prime \prime}$ ) (Fig.3b). Consequently, these results confirm the microscopic observations, indicating that the first case corresponds to micellar solutions; while in the second case true viscoelastic systems are obtained.

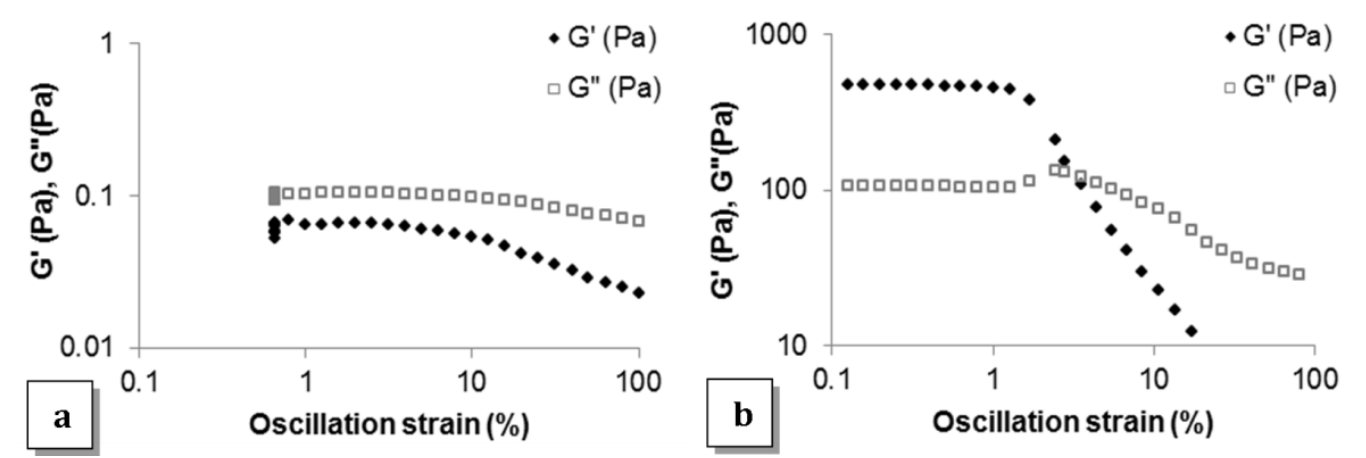

Figure 3. Storage $\left(G^{\prime}\right)$ and loss $\left(G^{\prime \prime}\right)$ moduli as a function of strain for a) liquid; b) semisolid formulations at $5 \%$ of emulsifier

As it was already explained, there exist two main types of lamellar phase: lamellar liquid crystals $\left(L_{\alpha}\right)$ and $\alpha$-gel $\left(L_{\beta}\right)$. Fairhurst et al. [18] describe the gel phase $\left(L_{\beta}\right)$ very similar to the lamellar liquid one, but with very high viscosity and presenting a gel-like rheology. The authors mention that these structures should not be confused with polymer gels since they are single phases. 
In the meantime, the $\mathrm{G}^{\prime \prime}$ curve shows a maximum (Fig.3b) in the markedly nonlinear range (around $3 \%$ of strain), featuring a gel structure [24,25]. This behaviour was described in case of various colloidal systems (for example xanthan solutions or emulsions), as able to form a weakly structured material due to their physicochemical properties [25-28]. Consequently, the viscoelastic response of 20/80 APG/FA is similar to the weak gel response, suggesting the idea of the $\alpha$-gel exclusive presence or its predominance over the liquid crystalline phase in the sample.

From the Fig.4, showing the results of the flow test, it can be clearly seen that APG $<F A$ are more viscous than APG $\geq F A$ over the analyzed shear rate ramp.

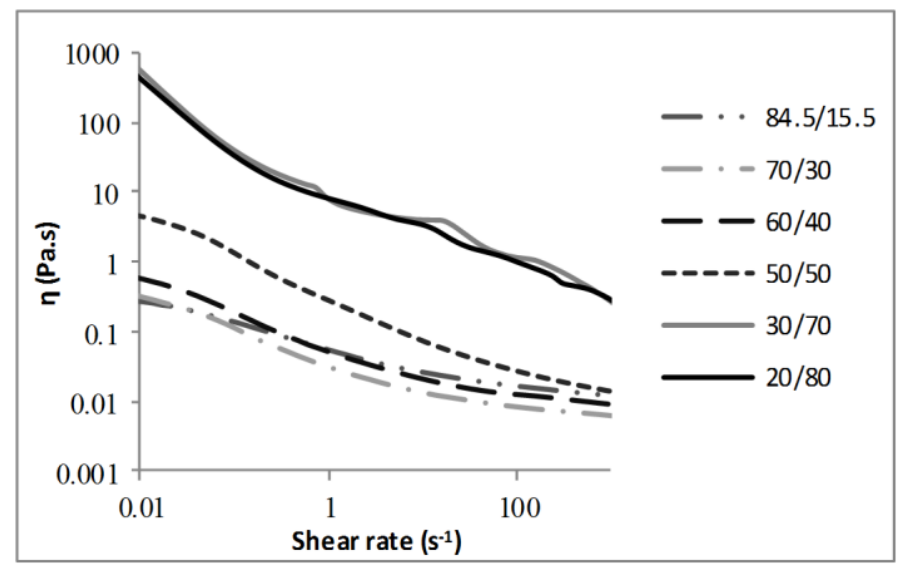

Figure 4. Viscosity as a function of shear rate for the series at $5 \%$ of emulsifier with various APG/FA ratios

When considering classical micellar solutions, they normally exhibit Newtonian rheological behaviour [29], but in the present example, it is obvious that despite low viscosity values, APG $\geq F A$ samples show a shear-thinning response. This phenomenon can be related to the fact that APG/FA mixture classically forms large cylindrical micelles that exhibit a shear-thinning behaviour, far different from classical ball-shaped micelles, with a smaller aggregation number, that remain mainly Newtonian [30-32]. At the same time, the viscosity of the cylindrical micellar solution is still much lower if compared to liquid crystals one.

The above results clearly point out the fact that increasing the FA ratio in the surfactant composition provokes the evolution of the micellar solution towards liquid crystals. This evolution also changes the flow behaviour of the systems.

\subsection{Liquid crystalline phases}

\subsubsection{Investigation of the microscopic structure}

Next, the region between $5 \%$ and $30 \%$ of surfactant is considered, corresponding to the presence of the liquid crystals (Fig.1). First of all, it was important to understand the mechanism of the formation of more consistent systems. Observations under both bright and polarized light microscopy were first envisaged. One can observe that for mixtures with APG $>F A$ no specific object was observed under the bright light (Fig.2 84.5APG/15.5FA at 30\%). On the contrary, under the polarized light, the fanlike and non-geometric structures are pointing at the formation of hexagonal liquid crystal phase [33]. These structures are evolving towards lamellar phases when oily streaks appear at 50/50 ratio [32] and finally, the Maltese Crosses at 20/80 [34]. Wide droplet dispersions, forming a network, are only developed if increasing the concentration of fatty alcohol up to APG $<F A$ in the surfactant mixture. Particle size distribution analysis, using SLS (Fig. 2), confirmed the presence of droplets in semisolid auto-emulsions for APG $\leq$ FA; this illustrates that the fatty alcohol also played the role of "oil phase", thus creating the pseudoemulsions. The median diameters of the pseudo droplets represented in number are quite similar for the analysed concentrations, being equal to $0.2-0.3 \mu \mathrm{m}$. However, the volume representation indicates that increasing the quantity of the surfactant in the solution is favouring the formation of few "bigger" fatty alcohol droplets.

To resume, three types of structures can be evidenced depending on APG/FA ratio at high concentrations in solutions:

- $\quad$ APG $>$ FA: asymmetric structures, corresponding to hexagonal phases as reported in the literature [35];

- $\quad$ APG <FA: presence of lamellar crystals, confirmed by the specific structures, called Maltese crosses [11,36]; 
- $\quad$ APG=FA: a mixture of strained Maltese crosses combined with asymmetric structures, illustrating the coexistence of both lamellar (spherulites and oily streaks $[37,38]$ ) and probably hexagonal liquid crystals, making this ratio a transit-like state between two elucidated types of liquid crystals.

From a general point of view, all these structures appear even more pronounced when emulsifier content increases.

The liquid crystals type also impacts the macroscopic properties of the analysed systems. The response to the frequency sweep test, applied on a liquid crystal containing systems, is different depending on its type. First, the linear viscoelastic region was obtained through the oscillatory test, and then the frequency sweep ramp was performed at a constant strain, which was chosen within the previously marked linear viscoelastic region of each sample.

Fig. 5 illustrates the different behaviours evidenced at $10 \%$ of the emulsifier for different APG/FA ratios:

- APG>FA: in the analysed zone of frequencies, the cross point of two moduli ( $G^{\prime}$ and $G^{\prime \prime}$ ) could be observed (Fig.5a), corresponding to the behaviour of hexagonal phases $[33,39,40]$. This information helps to clarify that the microscopic observations under the polarized light do not belong to lamellar phase;

- $\quad$ APG $<F A$ : storage modulus is parallel to loss modulus, corresponding to lamellar phase behaviour [41-43], thus confirming the microscopic observations (Fig.5b);

- $\quad$ APG=FA: these products showed a more lamellar like response to the solicitation, with parallel curves and weak frequency dependence of both $\mathrm{G}^{\prime}$ and $\mathrm{G}^{\prime \prime}$, but with lower values of both moduli (Fig.5c). These results could suggest two hypotheses:

1 The lamellar phases are still present in the mixture, but with containing more lamellar liquid crystals (and, therefore, less $\alpha$-gel) than the auto-emulsions with APG<FA

2 The partial presence of the hexagonal phases with $\alpha$-gel involves both $G^{\prime}$ and $G^{\prime \prime}$ decrease without lamellar liquid crystal formation.
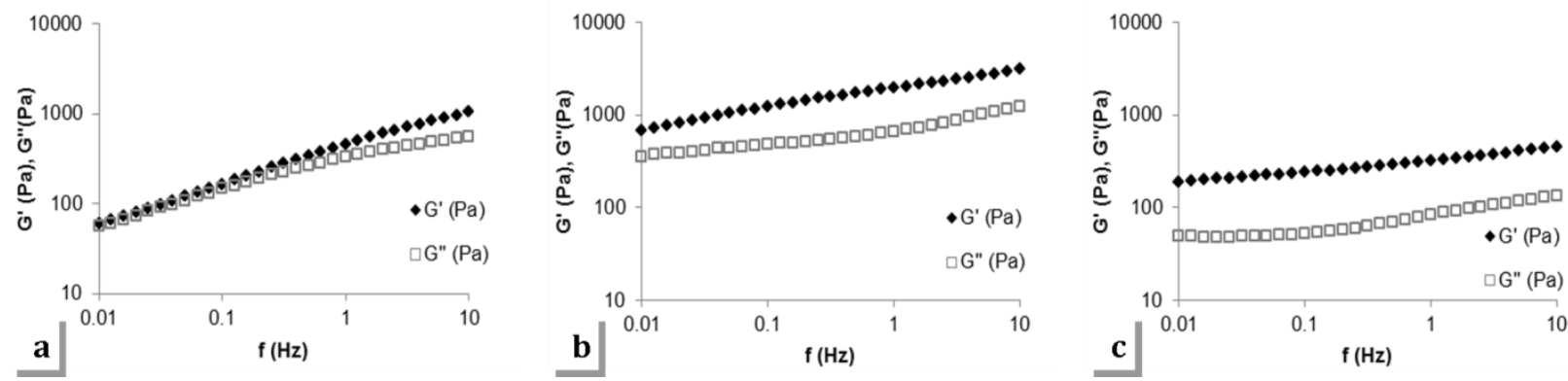

Figure 5. Frequency sweep test. Viscoelastic behaviour of the systems containing APG/FA ratio: a) 84.5/15.5; b) 20/80; c) 50/50

\subsubsection{Access to the liquid crystals organization through the wide-angle $\mathrm{X}$-rays diffraction technique}

While a frequency sweep test provides additional crucial information concerning the hexagonal and lamellar phases, it is inadequate to elucidate the type of lamellar phase present in the different investigated samples. For this reason, the use of wide-angle X-ray diffraction technique was necessary in order to access the exact arrangement of surfactant molecules in the liquid crystal systems.

Classically, the X-rays diffraction technique has been primarily applied to well-ordered crystalline materials to determine crystal structures, but today it is also used in the characterization of non- or semi-crystalline materials. In case of lyotropic liquid crystals, X-rays diffraction measurement gives access to the crystalline form of surfactants in a solvent.

Fig.6 shows the results of the WAXD analysis for three ratios, APG $<F A ; A P G=F A ; A P G>F A$, at $10 \%$ of emulsifier. The amorphous part was subtracted from the diffractogram and five most important peaks were then evidenced. The corresponding distances were then calculated via the Bragg's law (Table 2). 


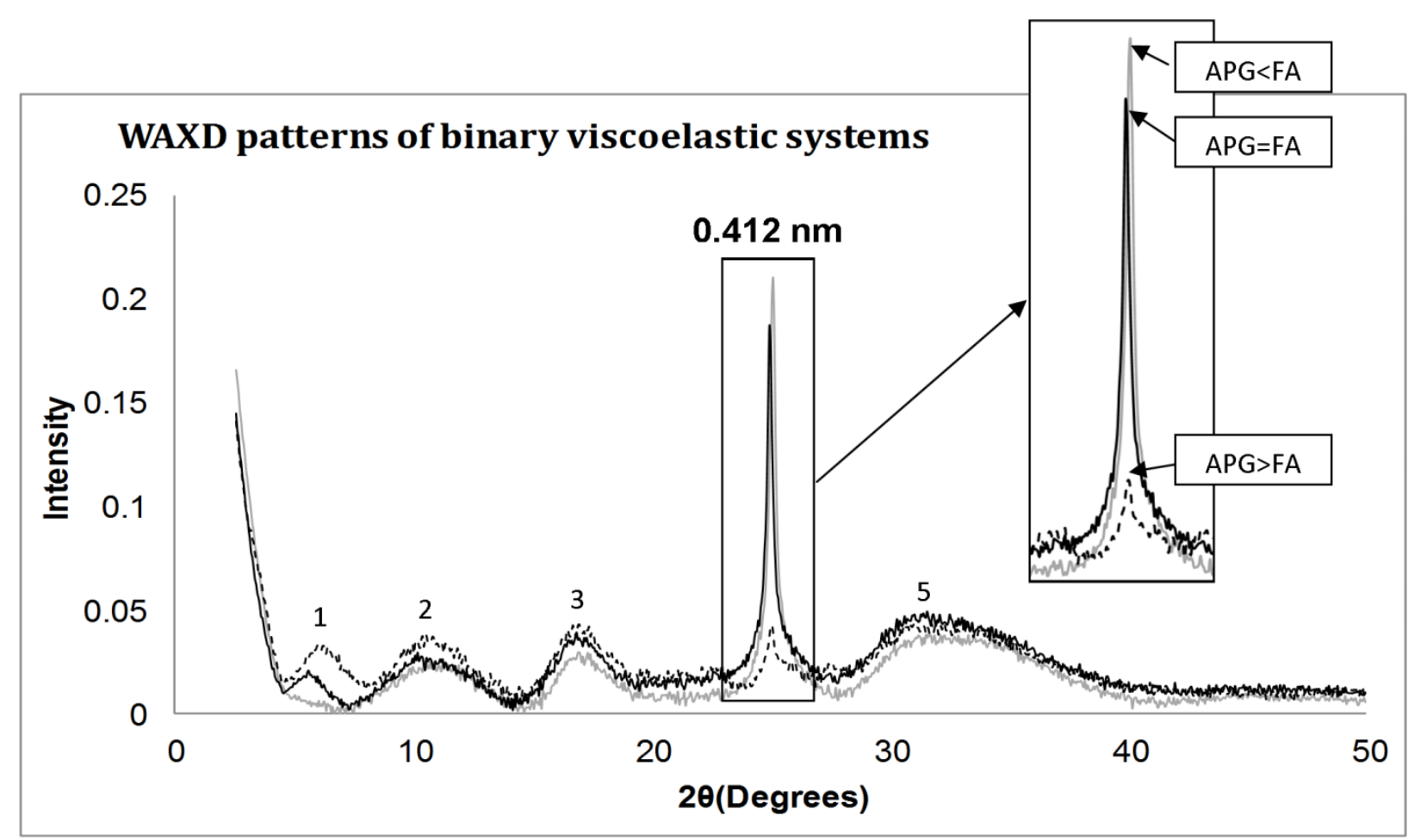

Figure 6. WAXD patterns of binary systems at $10 \%$ of the mixed emulsifier

Table 2. Measured repeated distances $\mathrm{d}(\mathrm{nm})$ of the peaks presented in Fig.6

\begin{tabular}{cccccc}
\hline Peak & $\mathbf{1}$ & $\mathbf{2}$ & $\mathbf{3}$ & $\mathbf{4}$ & $\mathbf{5}$ \\
\hline $\begin{array}{c}\text { Measured repeated } \\
\text { distance } \boldsymbol{d}(\mathrm{nm})\end{array}$ & 1.72 & 0.93 & 0.62 & 0.412 & 0.345 \\
\hline
\end{tabular}

Four peaks (1, 2, 3 and 5) can be described as diffuse halos thus illustrating a mainly amorphous like organization. This can be due to the matrix of the sample, containing mostly water as a solvent.

Valoppi et al. [44] identified the sharp peaks corresponding to fatty alcohol $\mathrm{C}_{18} \mathrm{OH}$ at $0.42 \mathrm{~nm}$ and $0.41 \mathrm{~nm}$, and the peak corresponding to $\mathrm{C}_{16} \mathrm{OH}$ at $0.418 \mathrm{~nm}$ for pure raw materials. Moreover, the authors proposed the X-rays diffraction patterns for the binary systems containing fatty alcohols and peanut oil as a solvent. In case of low fatty alcohol concentration in the oil (5\%), a diffuse halo was observed between $15^{\circ}$ and $25^{\circ}$, similar to one peak observed in the present study (peak 3 ).

The most important differences between the samples can be observed at $0.412 \mathrm{~nm}$ (peak 4), corresponding to $\alpha$-gel as reported in the literature $[18,45]$. Its quantity significantly decreases when the hexagonal phase is reached for APG $>$ FA.

The previous results from oscillatory test showed the lamellar behaviour of the intermediate phase, which is confirmed by WAXD. For APG=FA (50/50), the peak corresponding to $\alpha$-gel remains present with an intensity similar to the one corresponding to APG $<F A(20 / 80)$. These last results suggest the idea of interdependency between the ratio of fatty alcohol and the lamellar phase formation; it should represent at least $50 \%$ of the mixed surfactant, to form $\alpha$-gel in auto-emulsions.

The lamellar liquid phase $\left(L_{\alpha}\right)$, which is normally represented by a diffuse halo with its centre at $0.45 \mathrm{~nm}[18,46]$, was not observed on the diffractogram. This may be explained either by the overlapping of the signal at $0.45 \mathrm{~nm}$ with the intense peak at $0.412 \mathrm{~nm}$ or by the absence of lamellar liquid phase in such systems only consisting of surfactant and water. In this case, the second hypothesis proposed for the explanation of the rheological behaviour of APG=FA ratio is more likely to be true: at this ratio, there is a transition between the hexagonal phase towards $\alpha$-gel, without passing through the lamellar liquid crystal phase formation. 
In the literature, the $\alpha$-crystalline hexagonal formations are described by the diffraction spacing equal to $0.406 \mathrm{~nm}$ and 0.357 $\mathrm{nm}$ [47]. In our case, these two spacings are not clearly marked, suggesting the possible existence of hexagonal phase more in the liquid-like state. Consequently, a closer observation of WAXD results indicated that the hexagonal packing of APG molecules is rearranged into $\alpha$-gel by adding the fatty alcohol with the same chain length, making the system more viscoelastic and consistent. This is due to the specific molecular organization inside the $\alpha$-gel (Fig.7), with rigid, trans ordered alkyl chains (with only rotational freedom) and hexagonal mode of chains packaging $[18,47]$.
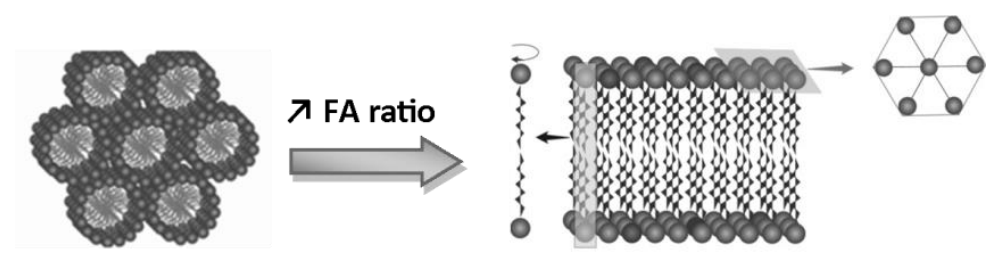

Figure 7. Reorganisation of hexagonal packing of APG molecules into $\alpha$-gel by adding fatty alcohol of the same chain length

\section{Conclusion}

The aim of this study was to investigate the phase behaviour of the $C_{16} C_{18}$ polyglucoside emulsifier coupled to $C_{16} C_{18}$ fatty alcohol as a co-surfactant. A certain number of studies were already exposed in the literature considering the investigation of APG behaviour alone or coupled to the fatty alcohol $[14,16,32,36,48,49]$. But in our case the $C_{16} C_{18} A P G / C_{16} C_{18} F A$ mixed emulsifier is produced from the natural source, so the understanding of its phase behaviour becomes more difficult due to its complex composition.

Depending on the APG/FA ratio and its concentration in solution different structures were described. A narrow instability zone, corresponding to a very small amounts of surfactant, evolves towards the $\alpha$-gel $\left(L_{\beta}\right)$ for the emulsifier with high fatty alcohol content $(A P G<F A)$, or passes through the micellar solution $\left(L_{1}\right)$ towards the hexagonal phase $\left(H_{1}\right)$, for the surfactant ratio dominated by APG (APG>FA). In addition, between the two zones corresponding to lamellar and hexagonal liquid crystals, a transition region prevails; it is characterized by the changes in the lamellar phase properties; this corresponds to $\alpha$-gel conversion to hexagonal packing when the necessary APG content ratio is reached.

In APG/FA mixed emulsifier, fatty alcohol plays a crucial role in lamellar phase formation. At 50 APG/50 FA ratio, fatty alcohol molecules owning a small hydrophilic head are easily arranged in bilayers between the APG molecules to form the lamellar organization. Next, by increasing the FA ratio, a specific system is obtained. Once the fatty alcohol is in excess, it plays the role of the pseudo droplets, surrounded by the lamellar gel. It draws consequently a specific pattern under the polarized light called Maltese Crosses.

From the fundamental and industrial point of views, these results demonstrate how controlling the ratio of a given emulsifier/co-emulsifier mixture offers the possibility to control the liquid crystalline form(s) of the system. This work brings complementary data when comparing to the literature dealing with the similar emulsifier at a fixed ratio. It helps the understanding of the phenomena happening at the structural, microscopic and macroscopic level governed by the mixed emulsifier.

\section{Conflicts of interest}

There are no conflicts to declare.

\section{Acknowledgements}

This work has been carried out in the context of the ALGRAAL, selected as Project of Excellence by the General Directorate for Competitiveness Industry and Services (DGCIS) in the 16th Appeal FUI (Fonds Unique Interministériel). The authors gratefully acknowledge the financial support of the FUI and the Région Normandie.

\section{References}

[1] M.J. Rosen, J.T. Kunjappu, Surfactants and Interfacial Phenomena, John Wiley \& Sons, 2012. 
[2] D. Myers, Surfactant Science and Technology, 3rd ed., John Wiley \& Sons, New Jersey, 2005.

[3] E. Dickinson, D.J. McClements, Advances In Food Colloids, Springer Science \& Business Media, 1995.

[4] B. Jönsson, B. Lindman, K. Holmberg, B. Kronberg, Surfactants and Polymers in Aqueous Solution, Wiley, 2000.

[5] T.F. Tadros, Applied Surfactants: Principles and Applications, John Wiley \& Sons, 2006.

[6] T.F. Tadros, Phase Behaviour of Surfactant Systems, in: Appl. Surfactants, Wiley-VCH Verlag GmbH \& Co. KGaA, 2005: pp. 53-72. http://onlinelibrary.wiley.com/doi/10.1002/3527604812.ch3/summary (accessed June 10, 2016).

[7] P.J. Collings, M. Hird, Introduction to Liquid Crystals: Chemistry and Physics, CRC Press, 1997.

[8] A.M.F. Neto, S.R.A. Salinas, The Physics of Lyotropic Liquid Crystals: Phase Transitions and Structural Properties., Oxford University Press, 2005.

[9] C. Rodriguez, H. Kunieda, Phase behaviour and microstructure of liquid crystals in mixed surfactant systems, in: Mix. Surfactant Syst. Second Ed., CRC Press, 2004.

[10] Catherine LeHen-Ferrenbach, Karlheinz Hill, Sugar-Based Surfactants for Consumer Products and Technical Applications, in: Sugar-Based Surfactants, CRC Press, 2008. http://www.crcnetbase.com/doi/abs/10.1201/9781420051674.ch1 (accessed December 2, 2015).

[11] S. Savic, G. Vuleta, R. Daniels, C.C. Müller-Goymann, Colloidal microstructure of binary systems and model creams stabilized with an alkylpolyglucoside non-ionic emulsifier, Colloid Polym. Sci. 283 (2004) $439-451$. doi:10.1007/s00396-004-1174-4.

[12] A.C.P. Duncke, T.O. Marinho, C.N. Barbato, G.B. Freitas, M.C.K. de Oliveira, M. Nele, Liquid Crystal Observations in Emulsion Fractions from Brazilian Crude Oils by Polarized Light Microscopy, Energy Fuels. 30 (2016) 3815-3820. doi:10.1021/acs.energyfuels.5b02943.

[13] S. Savic, M. Lukic, I. Jaksic, S. Reichl, S. Tamburic, C. Müller-Goymann, An alkyl polyglucoside-mixed emulsifier as stabilizer of emulsion systems: The influence of colloidal structure on emulsions skin hydration potential, J. Colloid Interface Sci. 358 (2011) 182-191. doi:10.1016/j.jcis.2011.02.049.

[14] M. Lukic, I. Jaksic, V. Krstonosic, N. Cekic, S. Savic, A combined approach in characterization of an effective w/o hand cream: the influence of emollient on textural, sensorial and in vivo skin performance, Int. J. Cosmet. Sci. 34 (2012) 140-149. doi:10.1111/j.1468-2494.2011.00693.x.

[15] D.B. Markovic, M. Tasic-Kostov, M. Lukic, T. Isailovic, V. Krstonosic, R. Daniels, S. Savic, Physicochemical Characterization and in vivo Skin Performance of a Novel Alkyl Polyglucoside Emulsifier in Natural Cosmetic Cream-Bases, Tenside Surfactants Deterg. 51 (2014) 133-145. doi:10.3139/113.110294.

[16] G. Platz, C. Thunig, J. Pölicke, W. Kirchhoff, D. Nickel, Phase behaviour of alkyl polyglucosides in combination with fatty alcohols and alkyl sulphates, Colloids Surf. Physicochem. Eng. Asp. 88 (1994) $113-122$. doi:10.1016/0927-7757(94)80091-X.

[17] C.C. Müller-Goymann, Liquid Crystals in Drug Delivery, in: J. Swarbrick, J.C. Boylan (Eds.), Encycl. Pharm. Technol. Vol. 20 - Suppl. 3, CRC Press, 2000.

[18] C.E. Fairhurst, S. Fuller, J. Gray, M.C. Holmes, G.J.T. Tiddy, D. Demus, J. Goodby, G.W. Gray, H.-W. Spiess, V. Vill, Lyotropic Surfactant Liquid Crystals, in: Handb. Liq. Cryst. Set, Wiley-VCH Verlag GmbH, 1998: pp. 341392. http://onlinelibrary.wiley.com/doi/10.1002/9783527619276.ch7d/summary (accessed July 27, 2016).

[19] A. Tardieu, V. Luzzati, F.C. Reman, Structure and polymorphism of the hydrocarbon chains of lipids: A study of lecithin-water phases, J. Mol. Biol. 75 (1973) 711-733. doi:10.1016/0022-2836(73)90303-3.

[20] G.M. Eccleston, D. Ofpharmacy, Multiple-phase oil-in-water emulsions, J Soc Cosmet Chem. (1990) 122.

[21] S. Fukushima, M. Yamaguchi, F. Harusawa, Effect of cetostearyl alcohol on stabilization of oil-in-water emulsion: II. Relation between crystal form of the alcohol and stability of the emulsion, ResearchGate. 59 (1977) 159-165. doi:10.1016/0021-9797(77)90350-2.

[22] H. Junginger, A.A.M.D. Akkermans, W. Heering, The ratio of interlamellarly fixed water to bulk water in 0 in W creams, J. Soc. Cosmet. Chem. 35 (1984) 45-57.

[23] M.A. Siddig, S. Radiman, S.V. Muniandy, L.S. Jan, Structure of cubic phases in ternary systems Glucopone/water/hydrocarbon, Colloids Surf. Physicochem. Eng. Asp. 236 (2004) 57-67. doi:10.1016/j.colsurfa.2004.01.023.

[24] D. Bais, A. Trevisan, R. Lapasin, P. Partal, C. Gallegos, Rheological characterization of polysaccharidesurfactant matrices for cosmetic O/W emulsions, J. Colloid Interface Sci. 290 (2005) 546-556. doi:10.1016/j.jcis.2005.04.044. 
[25] L. Gilbert, V. Loisel, G. Savary, M. Grisel, C. Picard, Stretching properties of xanthan, carob, modified guar and celluloses in cosmetic emulsions, Carbohydr. Polym. 93 (2013) 644-650. doi:10.1016/j.carbpol.2012.12.028.

[26] W.E. Rochefort, S. Middleman, Rheology of Xanthan Gum: Salt, Temperature, and Strain Effects in Oscillatory and Steady Shear Experiments, J. Rheol. 31 (1987) 337-369. doi:10.1122/1.549953.

[27] K. Hyun, S.H. Kim, K.H. Ahn, S.J. Lee, Large amplitude oscillatory shear as a way to classify the complex fluids, J. Non-Newton. Fluid Mech. 107 (2002) 51-65. doi:10.1016/S0377-0257(02)00141-6.

[28] K. Hyun, J.G. Nam, M. Wilhellm, K.H. Ahn, S.J. Lee, Large amplitude oscillatory shear behavior of PEO-PPOPEO triblock copolymer solutions, ResearchGate. 45 (2006) 239-249. doi:10.1007/s00397-005-0014-x.

[29] J. Munoz, C. Gallegos, V. Flores, Structure and rheology in surfactant systems: relationship between structure and rheological behaviour in surfactant water systems, Tenside Surfactants Deterg. 28 (1991) 204207.

[30] D. Nickel, T. Förster, W.V. Rybinski, Physicochemical Properties of Alkyl Polyglycosides, in: K. Hill, W. von Rybinski, G. Stoll (Eds.), Alkyl Polyglycosides, Wiley-VCH Verlag GmbH, 1996: pp. 39-69. http://onlinelibrary.wiley.com/doi/10.1002/9783527614691.ch4/summary (accessed July 29, 2016).

[31] B. Hoffmann, G. Platz, Phase and aggregation behaviour of alkylglycosides, Curr. Opin. Colloid Interface Sci. 6 (2001) 171-177. doi:10.1016/S1359-0294(01)00075-9.

[32] M.W. Sulek, T. Wasilewski, Tribological properties of aqueous solutions of alkyl polyglucosides, Wear. 260 (2006) 193-204. doi:10.1016/j.wear.2005.02.047.

[33] Y. An, J. Xu, J. Zhang, C. Hu, G. Li, Z. Wang, Z. Wang, X. Zhang, L. Zheng, Studies on the phase properties of lyotropic liquid crystals of Brij35/sodium oleate/oleic acid/water system: By means of polarizing microscope, SAXS, 2H-NMR and rheological methods, Sci. China Ser. B Chem. 49 (2006) 411-422. doi:10.1007/s11426006-2018-5.

[34] T. Scharf, Polarized Light in Liquid Crystals and Polymers, John Wiley \& Sons, 2007.

[35] M. Wlodzimierz Sulek, A. Bak, The Effect of Liquid Crystalline Structures on Antiseizure Properties of Aqueous Solutions of Ethoxylated Alcohols, Int. J. Mol. Sci. 11 (2010) 189-205. doi:10.3390/ijms11010189.

[36] S. Savić, M. Savić, S. Tamburić, G. Vuleta, S. Vesić, C.C. Müller-Goymann, An alkylpolyglucoside surfactant as a prospective pharmaceutical excipient for topical formulations: The influence of oil polarity on the colloidal structure and hydrocortisone in vitro/in vivo permeation, Eur. J. Pharm. Sci. 30 (2007) 441-450. doi:10.1016/j.ejps.2007.01.006.

[37] C. Li, J. He, J. Liu, Z. Yu, Q. Zhang, C. He, W. Hong, Self-assembly of lyotropic liquid crystal phases in ternary systems of 1,2-dimethyl-3-hexadecylimidazolium bromide/1-decanol/water, J. Colloid Interface Sci. 342 (2010) 354-360. doi:10.1016/j.jcis.2009.10.067.

[38] X.-W. Li, J. Zhang, B. Dong, L.-Q. Zheng, C.-H. Tung, Characterization of lyotropic liquid crystals formed in the mixtures of 1-alkyl-3-methylimidazolium bromide/p-xylene/water, Colloids Surf. Physicochem. Eng. Asp. 335 (2009) 80-87. doi:10.1016/j.colsurfa.2008.10.031.

[39] G. Montalvo, M. Valiente, E. Rodenas, Rheological Properties of the L Phase and the Hexagonal, Lamellar, and Cubic Liquid Crystals of the CTAB/Benzyl Alcohol/Water System, Langmuir. 12 (1996) 5202-5208. doi:10.1021/la9515682.

[40] F. Cordobés, J. Muñoz, C. Gallegos, Linear Viscoelasticity of the Direct Hexagonal Liquid Crystalline Phase for a Heptane/Nonionic Surfactant/Water System, J. Colloid Interface Sci. 187 (1997) 401-417. doi:10.1006/jcis.1996.4707.

[41] M.A. Siddig, S. Radiman, L.S. Jan, S.V. Muniandy, Rheological behaviours of the hexagonal and lamellar phases of glucopone (APG) surfactant, Colloids Surf. Physicochem. Eng. Asp. 276 (2006) 15-21. doi:10.1016/j.colsurfa.2005.10.004.

[42] Z. Németh, L. Halász, J. Pálinkás, A. Bóta, T. Horányi, Rheological behaviour of a lamellar liquid crystalline surfactant-water system, Colloids Surf. Physicochem. Eng. Asp. 145 (1998) 107-119. doi:10.1016/S09277757(98)00576-7.

[43] M. Zheng, Z. Wang, F. Liu, Q. Mi, J. Wu, Study on the microstructure and rheological property of fish oil lyotropic liquid crystal, Colloids Surf. Physicochem. Eng. Asp. 385 (2011) 47-54. doi:10.1016/j.colsurfa.2011.05.040.

[44] F. Valoppi, S. Calligaris, A.G. Marangoni, Phase Transition and Polymorphic Behavior of Binary Systems Containing Fatty Alcohols and Peanut Oil, Cryst. Growth Des. 16 (2016) 4209-4215. doi:10.1021/acs.cgd.6b00145. 
[45] D. Kalnin, G. Garnaud, H. Amenitsch, M. Ollivon, Monitoring fat crystallization in aerated food emulsions by combined DSC and time-resolved synchrotron X-ray diffraction 5 , Food Res. Int. 35 (2002) 927-934. doi:10.1016/S0963-9969(02)00155-2.

[46] K. Larsson, Crystal and liquid crystal structures of lipids, in: Food Emuls., Marcel Dekker Incorporated, 1976: pp. 39-66.

[47] G.M. Eccleston, M.K. Behan-Martin, G.R. Jones, E. Towns-Andrews, Synchrotron X-ray investigations into the lamellar gel phase formed in pharmaceutical creams prepared with cetrimide and fatty alcohols, Int. J. Pharm. 203 (2000) 127-139.

[48] D. Balzer, Alkyl polyglucosides, in: I.D. Robb (Ed.), Spec. Surfactants, Springer Netherlands, 1997: pp. 169207. http://link.springer.com/chapter/10.1007/978-94-009-1557-2_7 (accessed January 30, 2015).

[49] W. von Rybinski, Alkyl glycosides and polyglycosides, Curr. Opin. Colloid Interface Sci. 1 (1996) $587-597$. doi:10.1016/S1359-0294(96)80096-3. 